\title{
Inhibitory protection of bearing units of electric motors in animal husbandry
}

\author{
V.A. Butorin*, L.A. Saplin, A.M. Molchan, L.V. Lyakhovetskaya, and A.A. Tleuova \\ Federal State Budgetary Educational Institution of Higher Education "South Ural State Agrarian \\ University" Chelyabinsk, Russia
}

\begin{abstract}
The electric motor is always part of the agricultural production system, in particular the animal production system. Its purpose is to equip a technological object with energy to ensure the functioning of the production process. The weak link of electric motors used in animal production is the bearing assemblies due to their wear in the corrosive environment of the premises used in this industry. The aim of the work was to assess the effect of inhibitory protection on the reliability of the bearing assemblies of electric motors for the conditions of their operation in animal husbandry. A theoretical resource distribution of bearing assemblies was chosen, approximated by the three-parameter Weibull distribution. For two groups of bearing assemblies, with and without inhibitory protection, bench tests were carried out to simulate the conditions of animal husbandry. The distributions of the initial wear rate of bearings and the difference between the limiting and initial wear rates were obtained. Using the theoretical distribution, the parameters of Weibull distribution were established. Their analysis showed that the use of the inhibitor "Prana" increases the durability of bearings by $15 \%$, which indicates the advisability of using this protection in animal husbandry conditions.
\end{abstract}

\section{Introduction}

Up to $20 \%$ of electric motors fail in agriculture every year. At the same time, the largest percentage of failures in the agricultural sector falls on animal husbandry. Bearing assemblies are one of the main elements of electric motors that determine their performance [1].

In this regard, innovative solutions to increase the reliability of bearing assemblies of electric motors will improve the efficiency of processes and improve the quality of livestock products.

Significant values of relative humidity and aggressive gases form a corrosive environment in livestock buildings causing several types of corrosive wear [2, 3]. O.D. Goldberg shows that the wear of the bearing units of electric motors can be corrosive, abrasive, fatigue [4]. According to B.V. Petrov the main cause of wear of the bearing assemblies of electric motors is fretting corrosion [5].

${ }^{*}$ Corresponding author: butorin_chgau@list.ru 
One of the most effective ways to protect parts from corrosive wear is inhibitory protection. Corrosion inhibitors are chemical compounds, the presence of which in a corrosive environment in sufficient concentration, reduce the corrosion rate [6].

To assess the durability of the bearing assemblies of electric motors, it is necessary to justify the theoretical model to determine of the resource based on the results of bench tests. The choice of this model was based on the work [7]. Therefore, the function of the distribution density of the bearing resource $\varphi(T)$ is described by the expression that can be approximated with a sufficient accuracy degree by the three-parameter Weibull law, the distribution density of which has the form [8]

$$
f(T)=\frac{b}{a}\left(\frac{T-c}{a}\right)^{b-1} \exp \left[-\left(\frac{T-c}{a}\right)^{b}\right],
$$

where a is the parameter of the scale characteristic,

$\mathrm{b}$ is the parameter of the shape characteristic,

$\mathrm{c}$ is the parameter of the shear characteristic.

\section{Materials and methods}

The object of the study was an electric motor of the 4A series of standard size 4A100L4U3 (power $4 \mathrm{~kW}$, synchronous rotation speed $1500 \mathrm{rpm}$ ) with a V-belt transmission. From all the variety of factors affecting bearing wear in livestock conditions, the following main factors were selected: constant load X1, variable load X2, relative humidity X3. It was found that the factors affecting wear are distributed according to the normal law. Taking into account the random nature of the factors, the levels of their variation were selected for carrying out bench tests, which are presented in Table 1.

Table 1. Levels of varying factors during bench tests

\begin{tabular}{|c|c|c|c|c|c|c|}
\hline \multirow{3}{*}{$\begin{array}{l}\text { Planning } \\
\text { conditions }\end{array}$} & Constant gai & $\operatorname{kgf}(\mathrm{N})$ & Relative & $\operatorname{kgf}(\mathrm{N})$ & Relative 1 & idity, \% \\
\hline & \multicolumn{6}{|c|}{ Signification of factors } \\
\hline & $\begin{array}{l}\text { Natural, } \\
\quad P\end{array}$ & $\begin{array}{c}\text { Coded, } \\
X_{I}\end{array}$ & $\begin{array}{c}\text { Natural, } \\
\tilde{P}\end{array}$ & $\begin{array}{c}\text { Coded, } \\
X_{2}\end{array}$ & $\begin{array}{c}\text { Natural, } \\
\quad W\end{array}$ & $\begin{array}{c}\text { Coded, } \\
X_{3}\end{array}$ \\
\hline Basic level & $99.8(979)$ & 0 & $3.7(36)$ & 0 & 85 & 0 \\
\hline Variation interval & $30.4(298)$ & 1 & $3.6(35)$ & 1 & 15 & 1 \\
\hline Upper level & $130.2(1277)$ & +1 & $7.3(72)$ & +1 & 100 & +1 \\
\hline Lower level & $69.4(681)$ & -1 & $0.1(1)$ & -1 & 70 & -1 \\
\hline
\end{tabular}

Based on the established levels of variation of factors, Federal State Budgetary Educational Institution of Higher Education "South Ural State Agrarian University" developed a stand for testing the bearing assemblies of electric motors, which provides an effect on the wear of factors in the entire range of their impact, as well as a device for CIP monitoring of the wear of the bearing under study. The experiment planning matrix corresponded to the plan of the 23 full-factor experiment. For the experiment, two samples of bearing assemblies were prepared, installed on 8 electric motors. The first sample was without inhibitory protection, the second was with inhibitory protection.

The inhibitor "Prana" was added to the lubrication of bearings of the second group in the amount of $5 \%$ of its volume. The mechanism of action of this inhibitor was to transfer 
the bearing metal to a passive state. This was achieved by increasing the alkalinity of the medium when components were introduced into it, because of their influence, the electrode potential increases (i.e., the shift of its charge towards positive values). The growth of the electrode potential promoted electrostatic repulsion and further desorption of positively charged hydrogen ions $\mathrm{H}+$, in the process their concentration decreased, this brought the metal to a passive state [9].

\section{Research Results}

After the implementation of the full-factor experiment plan at the stand [10], regression equations for the bearing wear rate from the main influencing factors were obtained:

without inhibitory protection

$$
V_{0}=1,21+0,51 X_{1}+0,44 X_{2}+0,09 X_{3},
$$

with inhibitory protection

$$
V_{\mathrm{o}}=1,08+0,50 X_{1}+0,42 X_{2}+0,10 X_{3} .
$$

The experimental results were checked for reproducibility according to the Cochran's criterion, for the significance of the regression coefficients according to the Student's criterion, for the adequacy of the obtained model to the test results according to Fisher's criterion. The decoding of the regression equation was carried out using the formulas $[11,12]$.

$$
\begin{gathered}
X_{1}=\frac{P-99.8}{30.4}, \quad X_{2}=\frac{\tilde{P}-3.7}{3.6}, \quad X_{3} \\
=\frac{W-85}{15} .
\end{gathered}
$$

After decoding, we obtained the following polynomial dependences for bearings: without inhibitory protection

$$
V \text { o }=-1,42+0,0169 P+0,1215 \tilde{P}+0,0058 W,
$$

with inhibitory protection

$$
V_{\mathrm{o}}=-1,57+0,0164 P+0,1181 \tilde{P}+0,0067 W,
$$

The obtained equations, taking into account the distribution of the main influencing factors, made it possible to establish the average value of the initial wear rate Vo and its standard deviation $\sigma v 0$, as well as the value $\mathrm{Kv}$ for bearings without inhibitory protection and with inhibitory protection (see Table 2).

Table 2. Parameter values $V o, \sigma_{v o}$ and $K_{v}$

\begin{tabular}{|c|c|c|c|c|c|}
\hline \multicolumn{2}{|c|}{ Without inhibitory protection } & \multicolumn{3}{c|}{ With inhibitory protection } \\
\hline$V o, \mu \mathrm{m} / \mathrm{h}$ & $\sigma_{v o}, \mu \mathrm{m} / \mathrm{h}$ & $K_{v}, \mu \mathrm{m} / \mathrm{h}$ & $V o, \mu \mathrm{m} / \mathrm{h}$ & $\sigma_{v o}, \mu \mathrm{m} / \mathrm{h}$ & $K_{v}, \mu \mathrm{m} / \mathrm{h}$ \\
\hline $1.06 \cdot 10^{-3}$ & $0.20 \cdot 10^{-3}$ & $0.28 \cdot 10^{-3}$ & $0.93 \cdot 10^{-3}$ & $0.19 \cdot 10^{-3}$ & $0.27 \cdot 10^{-3}$ \\
\hline
\end{tabular}

Distribution density functions of initial wear rates for bearings: without inhibitory protection 


$$
\varphi\left(V_{0}\right)=2,0 \cdot \exp \left[-12,5 \cdot\left(V_{0}-1,06\right)^{2}\right]
$$

with inhibitory protection

$$
\varphi\left(V_{0}\right)=2,1 \cdot \exp \left[-13,85 \cdot\left(V_{0}-0,93\right)^{2}\right] .
$$

According to GOSNITI recommendations, the initial and limiting values of the bearing

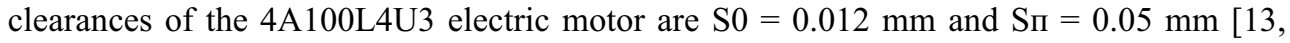
14], thus $\Delta \mathrm{S}=0.038 \mathrm{~mm}$.

The distribution density of the initial wear rates and the values of the Kv parameter made it possible to establish the resource distribution densities, which, after approximation by the Weibull three-parameter law (2), took the following form for bearings:

without inhibitory protection

$$
\varphi(T)=0,122 \cdot\left(\frac{t-18,1}{13,9}\right)^{0,7} \exp \left[-\left(\frac{t-18,1}{13,9}\right)^{1,7}\right], t \geq 19,1 \text { thousand hours }
$$

with inhibitory protection

$$
\varphi(T)=0,115 \cdot\left(\frac{t-22,5}{13,9}\right)^{0,6} \exp \left[-\left(\frac{t-22,5}{13,9}\right)^{1,6}\right], t \geq 22,5 \text { thousand hours }
$$

Graphically, the resource distributions of tested bearings without and with inhibitor protection are shown in Figure1.

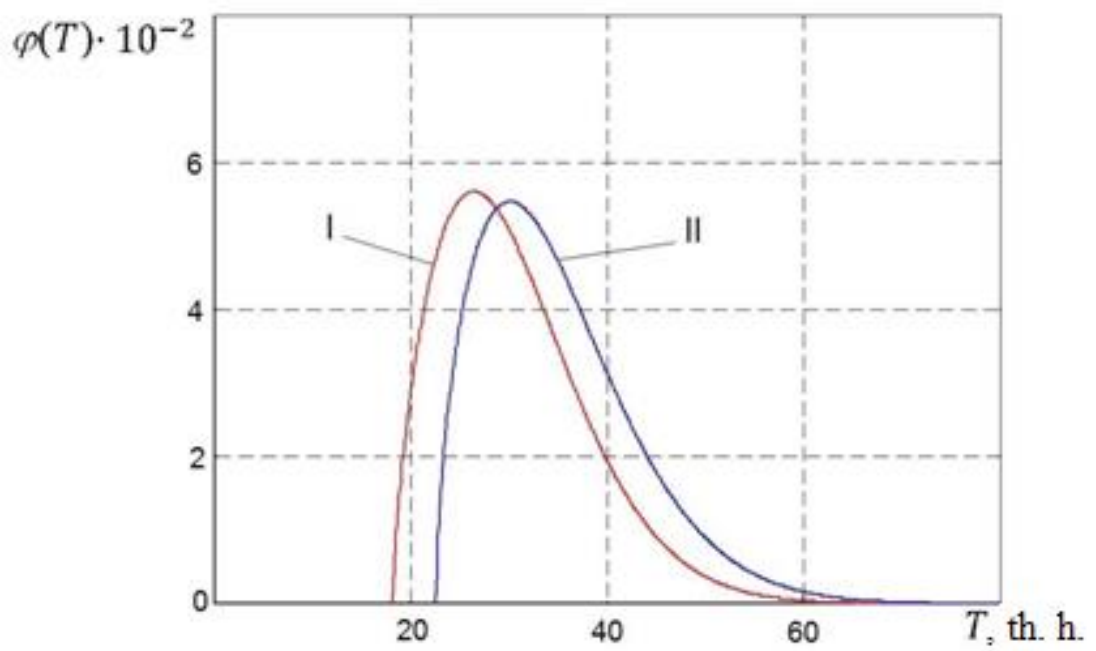

Fig. 1. Density of resource distribution of tested bearings: I - without inhibitory protection, II - with inhibitory protection.

The estimation of resource distribution parameters and its static characteristics of bearings without and with inhibitory protection are shown in Table 3. 
Table 3. Estimating the distribution parameters and the static characteristics of the resource of bearings of electric motors in animal husbandry.

\begin{tabular}{|l|c|c|c|c|c|}
\hline Protection type & $\begin{array}{c}\text { Average value T, } \\
\text { th } \mathrm{h}\end{array}$ & $\begin{array}{c}\text { Standard deviation } \sigma, \\
\text { th } \mathrm{h}\end{array}$ & \multicolumn{3}{|c|}{ Distribution parameters } \\
\cline { 4 - 6 } & 30.5 & 7.5 & 18.1 & 13.9 & 1.7 \\
\hline $\begin{array}{l}\text { Without } \\
\text { inhibitory } \\
\text { protection }\end{array}$ & 35.0 & 8.0 & 22.5 & 13.9 & 1.6 \\
\hline $\begin{array}{l}\text { With inhibitory } \\
\text { protection }\end{array}$ & & & & \\
\hline
\end{tabular}

\section{Conclusions}

The theoretical resource distribution function justified for application is approximated with a sufficient degree of accuracy by the three-parameter Weibull law. Numerous studies have proven the convenience of its use for approximating the distribution of bearing life.

The theoretical function of resource allocation justified for application with a sufficient degree.

According to the data obtained with the bench tests, it was found that the wear rate of bearings is described by the normal distribution law. The analysis of the research results on the average values of the resource shows that the use of protection of bearing assemblies with the use of the inhibitor "Prana" can increase its value by $15 \%$. The results obtained show the expediency of using the inhibitory protection of the bearing assemblies of electric motors used in animal production.

\section{References}

1. G.P. Eroshenko, N.P. Kondrat'eva, Operation of electrical equipment, 336 (M., INFA$\mathrm{M}, 2014)$

2. S. Aggarwal, R.K. Pandey, Industrial lubrication and tribology, 70(8), 1388-1395 (2018) doi:10.1108/ILT-10-2017-0302.

3. G.Y. Gao, Z.W. Yin, D. Jiang et al., Tribology international, 75, 31-38 (2014) doi:10.1016/j.triboint.2014.03.009.

4. O.D. Gol'dberg, S.P. Helenskaya, Reliability of electrical machines, 228 (M., Izdatel'skij centr i Akademiya, 2010)

5. B.V. Petrov, V.V. Lapushanskij, Investigation of the influence of technological errors on the damageability of seats of parts of bearing assemblies of electrical machines, 185 (Kiev, Nauchnye trudy USKHA, 1977)

6. L.E. Cygankova, V.I. Vagdorovich, A.P. Pozdnyakov, Metal corrosion inhibitors, 190 (Tambov, Izdatel'stvo TGU, 2001)

7. V.A. Butorin, Predicting the durability of bearing assemblies of asynchronous motors, 11 (Elektrotekhnika, 1998)

8. A.S. Grunichev, A.I. Mihajlov, Ya.B. Shor, Tables for calculating reliability with the Weibull distribution, 64 (M., Izdatel'stvo standartov, 1974) 
9. O.I. Golyanickij, G.A. Gonn, V.R. Gofman, Corrosion protection of equipment and structures with oils with Prana additive. Abstracts of the scientific conference "Experience of corrosion protection of building structures of equipment for industrial buildings and structures, DNTP", Chelyabinsk, (1976)

10. K. Hinkelmann, O. Kempthorne, Design and analysis of experiments, Introduction to experimental design, 1 (Wiley, Hoboken, 2007)

11. M. Morris, Design of experiments: an introduction based on linear models (Chapman and Hall, New York, 2010)

12. Geoffrey M. Clarke, Robert E. Kempson, Introduction to the design and analysis of experiments (Wiley, New York, 2010)

13. V.A. Butorin, Predicting the reliability of the restoration of electrical equipment, 139 (Chelyabinsk, CHGAU, 2004)

14. Electric motors asynchronous 4A series. Technical requirements for overhaul. TK70.0002.003, 85, 92 (M., GOSNITI, 1986) 